\title{
The surface of particles in Tamagawa estuary and Tokyo Bay and their influence on the distribution of trace elements
}

\author{
TASUKU AKAGI ${ }^{1}$ and HiROKI HARAGUCHI ${ }^{2}$ \\ ${ }^{1}$ Laboratory of Chemistry, Faculty of General Education, Tokyo University of Agriculture and Technology, \\ Saiwai-cho, Fuchu, Tokyo 183, Japan \\ ${ }^{2}$ Department of Applied Chemistry, Faculty of Engineering, Nagoya University, Chikusa-ku, Nagoya 464, Japan
}

(Received May 18, 1992; Accepted February 18, 1994)

\begin{abstract}
The surface and bulk chemical composition of suspended particles (SP) from the Tamagawa estuary and Tokyo Bay have been studied. X-ray photospectroscopy (XPS) was used for the surface analyses. By comparison with bulk analysis, it was found that there was a surface layer enriched in organic matter and manganese, and that such the particles were coexisting. Silica may also be adsorbed onto the surface, but is depleted relative to the bulk nevertheless. The organic matter in the surface is considered to be humic acids from its chemical composition, and becomes the dominant substance on the surface with increasing depth and distance offshore, overwhelming silicates and oxides. The effect of such particles on dissolved trace metals was investigated by comparing their concentration gradients with the coverage of humic acid, silicates and oxides in the surface. The concentration gradients of dissolved $\mathrm{Ni}, \mathrm{Cu}$ and $\mathrm{Zn}$ correlate better with the surface areas of $\mathrm{Al}, \mathrm{Fe}$ and $\mathrm{Mn}$ than with that of organic matter, suggesting the former are more effective adsorbers of metals than the latter.
\end{abstract}

\section{INTRODUCTION}

Trace elements in estuarine waters are involved in multiple reactions with other substances. Many studies have been conducted in order to investigate the behavior of trace metals in estuarine areas. The complicated behavior of materials in this environment has given some apparently inconsistent observations, as reviewed by Bewers and Yeats (1981).

Some basic reactions have been deduced from the investigation of the behaviour of trace elements in such areas. Colloidal particles and the scavenging effect have been focused on by Fox and Wofsy (1983), Hunter and Leonard (1988) and Moran and Moore (1989). The adsorption of dissolved species on sedimentary particles has been pointed out (Morris et al., 1986). Feely et al. (1983) reported that manganese oxide, probably on the surface of suspended particles (SP), adsorbs dissolved trace elements. The flocculation triggered by dissolved organic matter and iron was elucidated by
Sholkovitz (1976) and Sholkovitz et al. (1978). The surface of SP has been pointed out as a possible adsorber of dissolved species (Burton, 1976; Duinker, 1980; Feely et al., 1983; Morris et al., 1986), but the surfaces have not been investigated from this point of view.

We have been measuring elemental distributions in dissolved and particulate phases in the Tamagawa River estuary, one of the largest estuaries opening into Tokyo Bay. The Tamagawa River discharges a great amount of domestic and industrial wastes into Tokyo Bay. The behaviour of heavy metals in such areas is of importance when considering the input of river-borne materials to the ocean. We have previously reported that the distribution of each dissolved trace element shows spatial diversity (Akagi and Haraguchi, 1984), and that the surface composition of SP changes dramatically depending on the sampling location and depth (Akagi et al., 1985a). In this paper, we will focus on the surface of SP and discuss the relation between the distribution of 
dissolved trace elements and the composition of the surface layer.

\section{EXPERIMENTAL}

\section{Samples}

Samples were collected in November 1982 in the Tamagawa River estuary and Tokyo Bay. The sampling points were located on a line from the river mouth to $6 \mathrm{~km}$ offshore (Fig. 1). The positions of the sampling points and their depths are summarized in Table 1, along with salinity. All the samples were filtered through Nuclepore filters (pore size: $0.4 \mu \mathrm{m}$ ) on the boat immediately after sampling and stored at $\mathrm{pH} 2$ with nitric acid. The filters were dried and stored in a refrigerator for subsequent analysis of SP. Duplicate sub-samples were used for the measurement of the total surface area of SP without filtration.

\section{Chemicals and cleaning}

All the reagents used were of analytical grade or higher. All the acids were specially purified for trace metal analysis, purchased from Wako Chemical Co., Ltd. Sodium hydroxide of Suprapur grade from Merck and gallium metal of $99.99 \%$ purity from Nakarai Chemical were used to preconcentrate trace metals from solution (Akagi et al., 1985b). Standard solutions for inductively coupled plasma atomic emission spectrometry (ICP-AES) analysis were prepared by dissolving corresponding metals, oxides or salts.

Glassware was soaked in $5 \mathrm{M}$ nitric acid for

Table 1. Sampling locations and depths

\begin{tabular}{ccccc}
\hline $\begin{array}{c}\text { Station } \\
\text { No. }\end{array}$ & $\begin{array}{c}\text { Distance } \\
(\mathrm{km})\end{array}$ & $\begin{array}{c}\text { Water } \\
\text { depth }(\mathrm{m})\end{array}$ & $\begin{array}{c}\text { Sampling } \\
\text { depth }(\mathrm{m})\end{array}$ & Salinity \\
\hline \multirow{2}{*}{1} & -2.0 & 3 & 0 & 6.7 \\
& & & 3 & 27.9 \\
2 & 0.4 & 10 & 0 & 19.6 \\
& & & 4 & 31.6 \\
& & & 7 & 32.1 \\
3 & 2.2 & 22 & 10 & 32.39 \\
& & & 5 & 26.5 \\
& & & 11 & 30.3 \\
& & & 16 & 33.84 \\
& & & 20 & 34.00 \\
4 & 5.7 & 28 & 0 & 30.2 \\
& & & 10 & 31.1 \\
& & & 20 & 33.94 \\
& & & 25 & 34.09 \\
\hline
\end{tabular}

${ }^{a}$ Distance from the river mouth towards the Bay.
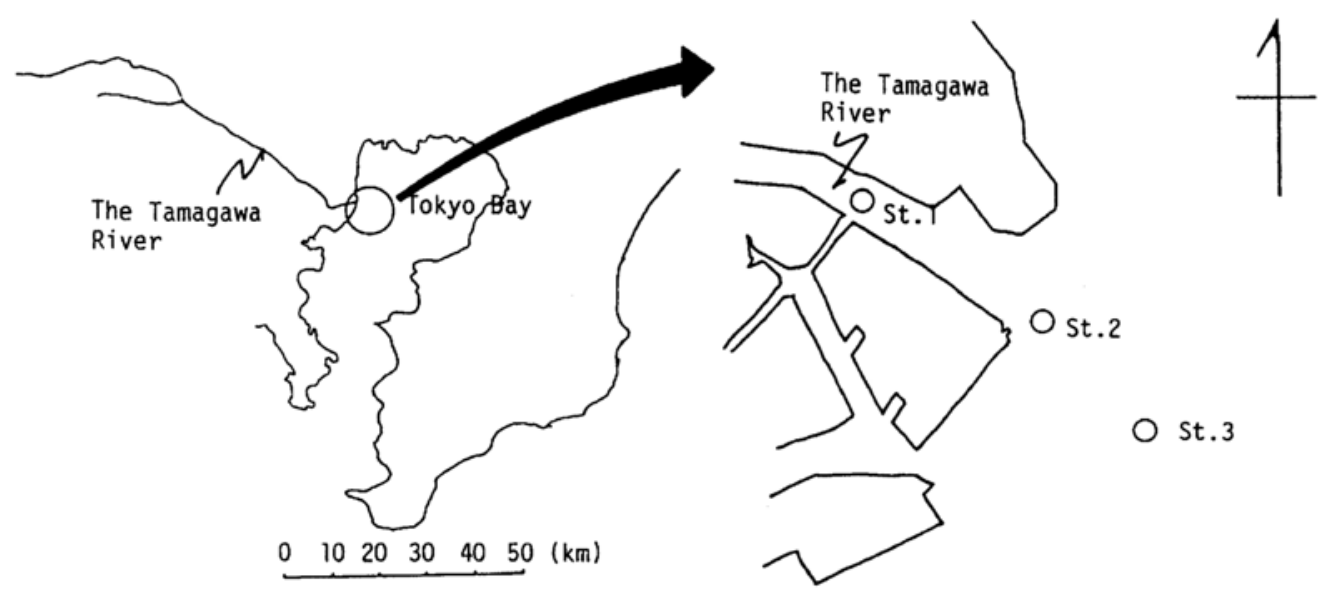

St. $4 \mathrm{O}$

$\begin{array}{lllllll}0 & 1 & 2 & 3 & 4 & 5 & (\mathrm{~km})\end{array}$

Fig. 1. Location of sampling points in the Tamagawa River estuary and Tokyo Bay. 
more than 1 week and rinsed well with pure water before use. Polyethylene bottles for sample storage were cleaned in the same way after pretreatment with acetone.

\section{Apparatus}

The ICP-AES system used was a Plasma AtomComp Mk II, Jarrell-Ash Co., Ltd. The operating conditions and wavelengths were the same as those previously reported (Akagi et al., 1985b). For X-ray fluorescence (XRF) analysis, a TEFA 6110 system of non-dispersive type (Ortec Inc., U.S.A.) with a Mo anode and Mo filter was used. An ESCA Lab. 5 system from VG Co., Ltd. was used for XPS analysis, with $\mathrm{AlK} \alpha$ and $\operatorname{MgK} \alpha$ excitation sources. The operating conditions for XRF and XPS systems have been briefly described in earlier papers (Akagi and Haraguchi, 1986; Akagi et al., 1985a). For the measurement of the total surface area of SP, a Shimadzu spectrophotometer, UV-3A, was used. The wavelength was set at 660 $\mathrm{nm}$. The length of the sample cell was $10 \mathrm{~cm}$.

\section{Procedures for elemental analyses}

Dissolved metals The details of the preconcentration procedure have been described elsewhere (Akagi et al., 1985b). One $\mathrm{ml}$ of $5 \mathrm{mg}$ $\mathrm{Ga} / \mathrm{ml}$ solution was added to 11 of filtered seawater. The $\mathrm{pH}$ was adjusted to 9 with $9 \mathrm{M}$ sodium hydroxide under continuous agitation and the solution left standing for several hours. The precipitate was collected on a $0.4 \mu \mathrm{m}$ Nuclepore filter and washed with $20 \mathrm{ml}$ of pure water. Finally it was dissolved in $2.5 \mathrm{ml}$ of $1 \mathrm{M}$ hydrochloric acid and made up to exactly $5 \mathrm{ml}$ with pure water. The resulting solution was analysed by ICP-AES. The precision of the measurements of $\mathrm{Al}, \mathrm{Mn}, \mathrm{Fe}, \mathrm{Ni}$, $\mathrm{Cu}$, and $\mathrm{Zn}$ is assumed to be as good as $5 \%$ mostly, and that of $\mathrm{Ti}$ and $\mathrm{Co}$, whose concentrations are close to the detection limits of the method (Akagi et al., 1985b), can vary from $10 \%$ to $30 \%$, depending on the concentrations.

Bulk and surface composition of SP The filter on which SP were collected was used for XRF and XPS measurements after drying. The calibration curve for XRF analysis was prepared by analysing some of the typical samples by ICP-AES after complete digestion. For the conversion of XPS peak intensities to their elemental concentration ratios, the conversion coefficients measured by Seyama and Soma (1982) for the same instrument were used. The error caused by the uncovered filter was corrected by using the peak intensity for bromine contained in the Nuclepore filter. The procedures for XRF and XPS measurements appear in our earlier papers (Akagi and Haraguchi, 1986; Akagi et al., 1985a). The precision of the XPS analysis depends on the concentration and the integration time. We chose the integration time in order to determine $\mathrm{Mn}$ with a precision better than $10 \%$, where the precisions of $\mathrm{Cu}, \mathrm{Zn}$ and $\mathrm{Ti}$ are assumed to be about $30 \%$. The precision of the $\mathrm{XRF}$ analysis is better than $10 \%$ for heavier elements.

\section{Measurement of total surface area of suspended particles}

The conventional technique for the surface area measurement is based on the amount of gas adsorbed on particles (BET method). This method did not seem suitable for the present study because the sample would have to be dried, which would change the structure and shape of the SP. The total surface area required in the present study corresponds to surface area of particles in suspension, over which dissolved species actually interact with them. Such a measurement can be made spectrophotometrically, on the assumption that optical absorbance is proportional to total surface area. The spectrophotometric method, however, does not provide an exact value of total surface area, because it depends on the size of particles and the wavelength used (Okami et al., 1982; Takematsu et al., 1979). Nevertheless, we adopted this method, because the results obtained would be expected to be more representative of the surface involved in reactions with dissolved species.

Measurement of the surface area of the SP was done within 5 hours after sampling. The water was agitated and then transferred into an optical cell, whose absorbance at $660 \mathrm{~nm}$ was measured. The factor to convert absorbance to total surface area 
was obtained using standard particles made of polystyrene sphere of known size $(1.1 \mu \mathrm{m})$ purchased from Particle Information Services, Inc., U.S.A.

\section{RESUlts AND Discussion}

Chemical composition of the surface of suspended particles

The data for molar fractions of elements on the surface of SP are summarized in Table 2. The decreases in $\mathrm{Si}, \mathrm{O}, \mathrm{Al}$, and $\mathrm{Fe}$ and the increase in $\mathrm{C}$ with distance from the river mouth are obvious. No shifts in binding energy were observed for all the samples in this area. From the binding energies (N 1s 399.3-399.7 eV; C 1s $284.8 \mathrm{eV}$; Si 2s
$153.0 \mathrm{eV} ; \mathrm{Al} 2 \mathrm{p}$ 73.9-74.2 eV; Fe 2p 711.0-712.0 $\mathrm{eV}$; Mn 2p 641.3-642.0 eV), it can be deduced that $\mathrm{N}$ and $\mathrm{C}$ are present mainly in amino acids and hydrocarbons, respectively, and that $\mathrm{Si}, \mathrm{Al}, \mathrm{Fe}$ and $\mathrm{Mn}$ are present as their oxides (Akagi et al., 1985). The distributions of $\mathrm{C} / \mathrm{N}$ and $\mathrm{C} / \mathrm{Si}$ ratios along the section surveyed are shown in Fig. 2, clearly demonstrating spatial changes in elemental composition. Roughly speaking, $\mathrm{C} / \mathrm{Si}$ increases with depth and distance from the river mouth (Fig. 2(a)). In deep water, $\mathrm{C} / \mathrm{Si}$ sometimes had lower values than in the water above, indicating the resuspension of sediments. In the greater part of the area studied, $\mathrm{C} / \mathrm{N}$ values were rather constant, between 7 and 10 (Fig. 2(b)). It was highest near the bottom at Stn. 4, perhaps due to water or SP of different

\section{Station No.}

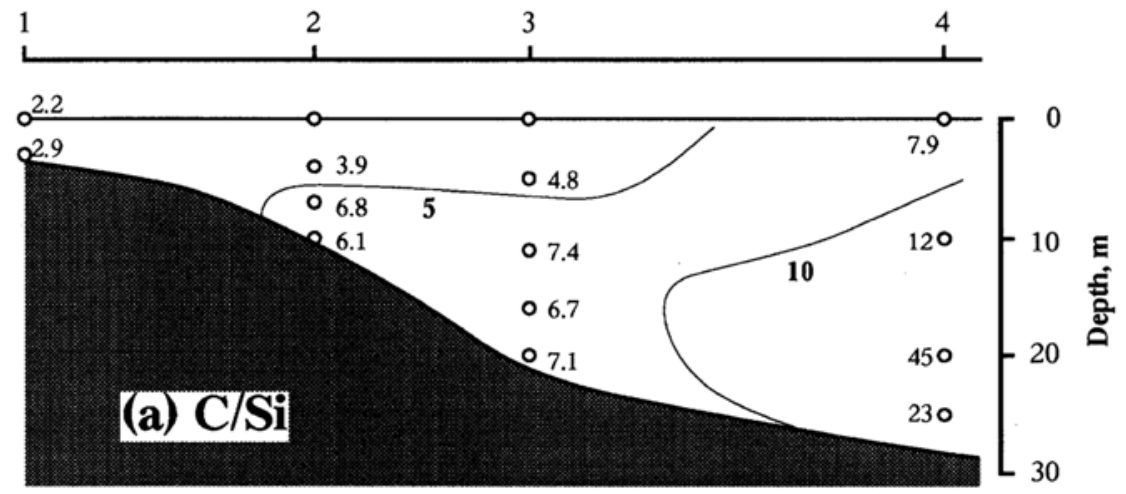

Station No.

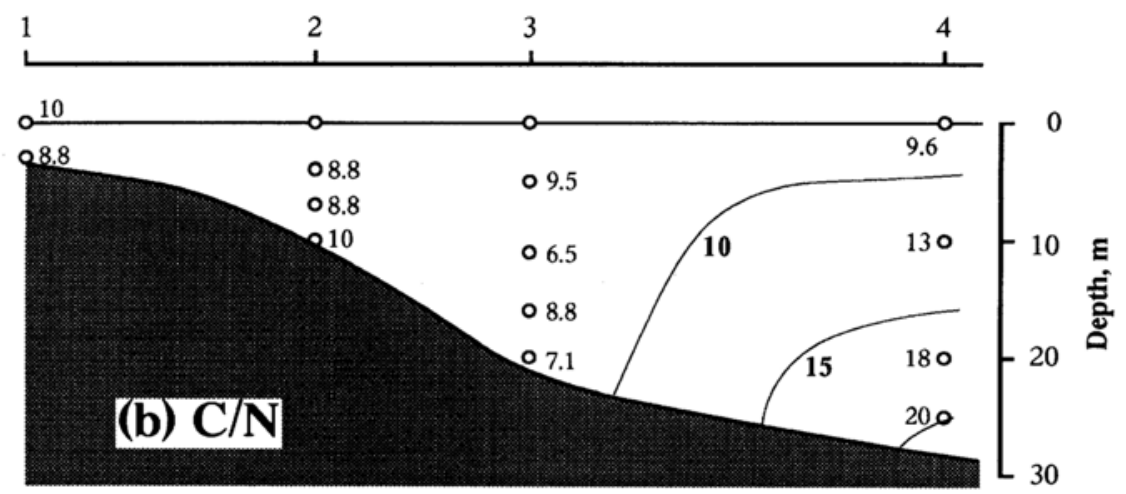

Fig. 2. Distribution of elemental molar ratios (a) C/Si and (b) C/N for the surface of SP in the Tamagawa River estuary and Tokyo Bay. 

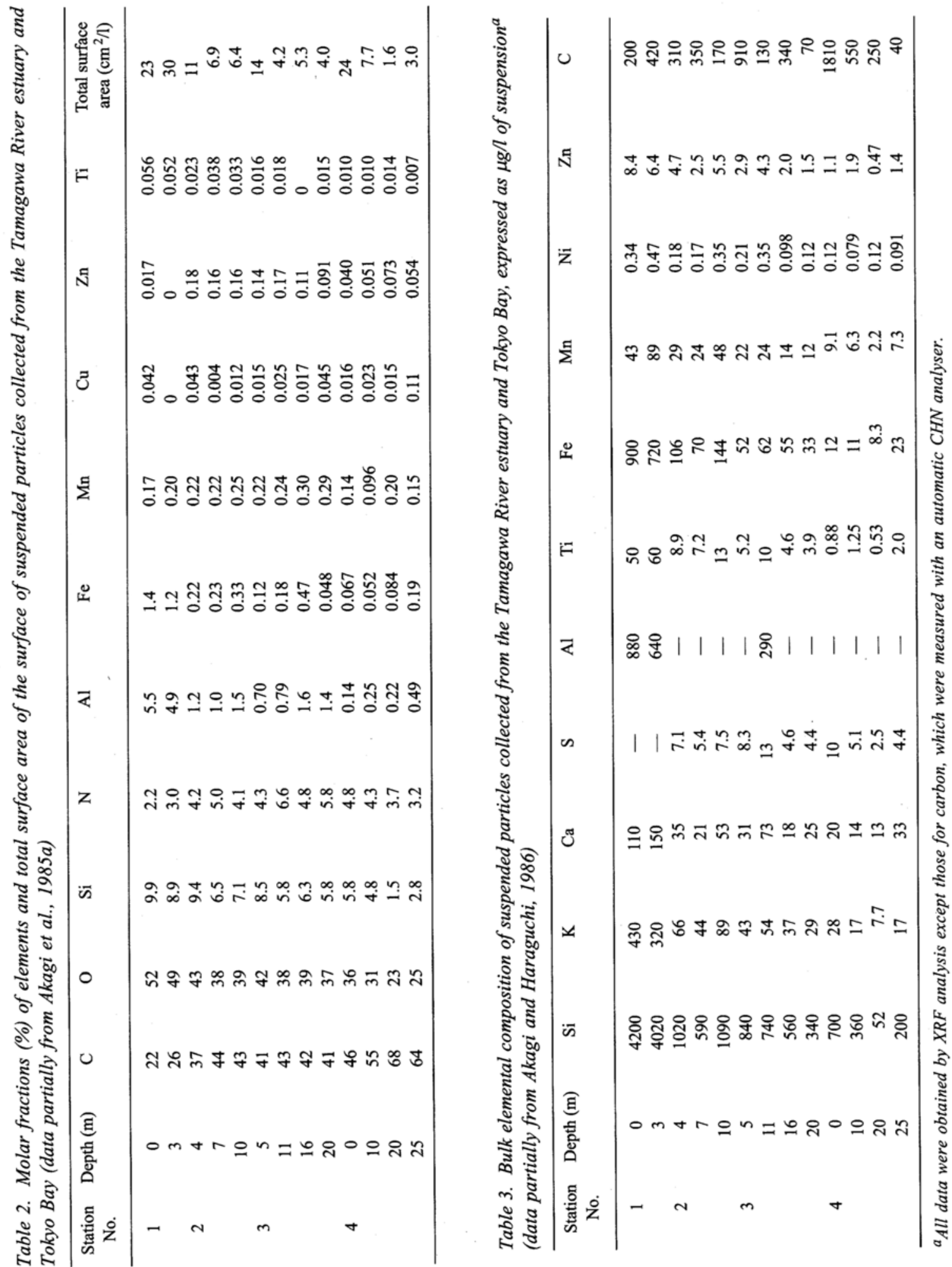


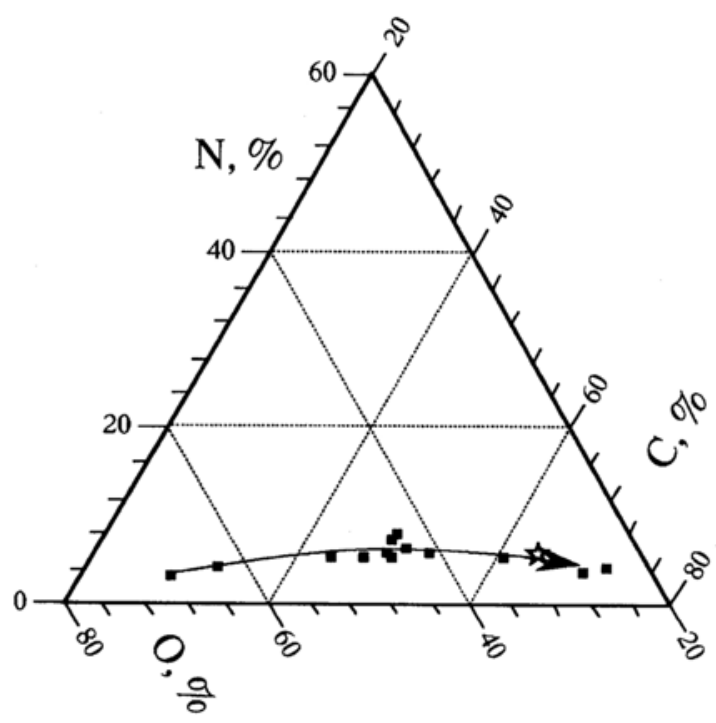

Fig. 3. Trend in chemical composition of the surface of SP with increasing depth and distance offshore (in Mole\%) in the Tamagawa River estuary and Tokyo Bay. The asterisk in the figure indicates the composition of humic acids reported for Tokyo Bay (Saito and Hayano, 1980).

origin. The triangle diagram for $\mathrm{C}, \mathrm{N}$ and $\mathrm{O}$ (Fig. 3) shows that, with increasing depth and distance offshore, the chemical composition of the surface of SP approaches that reported for humic acids from Tokyo Bay (Saito and Hayano, 1980). Humic acids are unstable in seawater and likely to form SP or be adsorbed onto SP.

Comparison of elemental composition between bulk and surface of suspended particles and models of the comparison

Table 3 summarizes the chemical composition of the bulk of SP by weight. The bulk and surface chemical compositions of SP were compared using the data listed in Tables 2 and 3, after converting the data in Table 2 to the values expressed by weight. Figure 4 compares their $\mathrm{Ti}, \mathrm{Fe}, \mathrm{Mn}$ and $\mathrm{C}$ ratios to Si. The straight lines in Fig. 4 represent the case where the ratios are the same in both the surface and the bulk of SP, in other words SP are homogeneous in terms of the ratio in question. From these diagrams it is obvious that the surface of SP is different from the bulk in composition.
One can see that the points for $\mathrm{Ti} / \mathrm{Si}, \mathrm{Fe} / \mathrm{Si}$ and $\mathrm{Mn} / \mathrm{Si}$ seem to form similar continuous curves with kinks. As far as the surface of SP is concerned, the models interpretating the shape of curves have to involve only the number, size and structure of SP, and other factors such as settling out of particles do not affect the shape of curves in the diagram. In the following section it is shown that even the simplest model involving the number, size and structure of SP can explain the shape of these curves to some extent.

The two simple models we examined are (a) the growth of a uniform coat on a uniform core (the growing coat model) and (b) the mixing of two different groups of particles of different sizes (the two-particle mixing model). The two models are shown schematically in Fig. 5. The growing coat model starts with a uniform core. A uniform coat, which is different from the core in the chemical composition, develops on the core. The two-particle mixing model, on the other hand, involves two different groups of particles. One group has a different size and a chemical composition from the other. Smaller particles have more influence on the result of the XPS analysis, whereas larger particles have more influence on the result of the XRF analysis. The calculations for the two models are outlined in the following.

Calculation of the loci for the growth of a uniform coat on a uniform core (Model a) The elemental ratios of $M_{1} / M_{2}$ for the surface and bulk analyses are:

$$
\begin{aligned}
&\left(\frac{\left[M_{1}\right]}{\left[M_{2}\right]}\right)_{\text {bulk }}= \frac{\left[M_{1}\right]_{\text {coat }}+\left[M_{1}\right]_{\text {core }}}{\left[M_{2}\right]_{\text {coat }}+\left[M_{2}\right]_{\text {core }}} \\
&= \frac{\left[\left(1+\frac{d r}{r}\right)^{3}-1\right] C_{\text {coat }}^{M_{1}}+C_{\text {core }}^{M_{1}}}{\left[\left(1+\frac{d r}{r}\right)^{3}-1\right] C_{\text {coat }}^{M_{2}}+C_{\text {core }}^{M_{2}}} \\
&\left(\frac{\left[M_{1}\right]}{\left[M_{2}\right]}\right)_{\text {surface }}=\left(\frac{\left[M_{1}\right]_{\text {coat }}+\left[M_{1}\right]_{\text {core }}}{\left[M_{2}\right]_{\text {coat }}+\left[M_{2}\right]_{\text {core }}}\right)_{\text {depth }<d s}
\end{aligned}
$$

when $d r \leq d s$ 


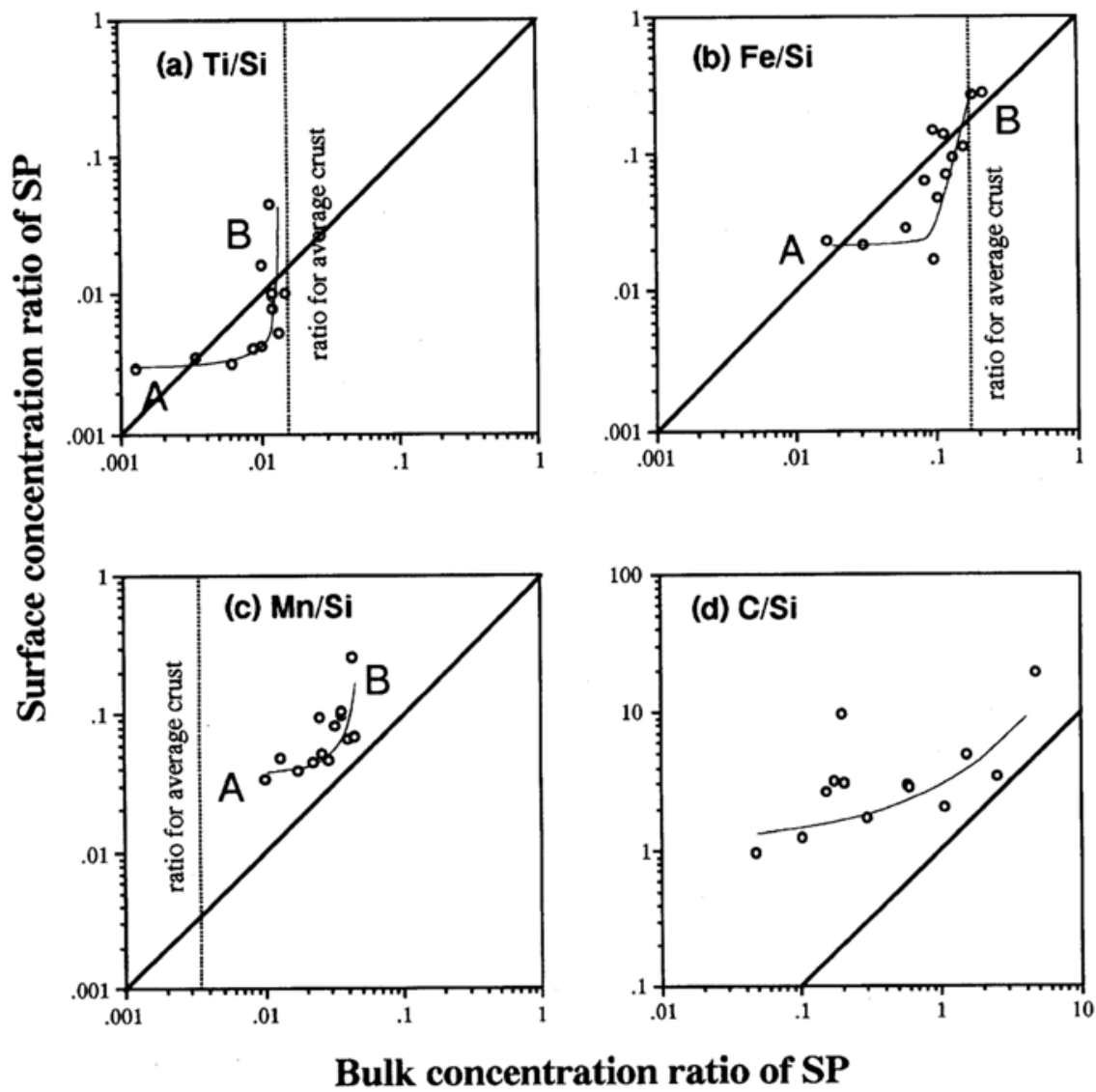

Fig. 4. Ratios of (a) Ti/Si, (b) Fe/Si, (c) Mn/Si and (d) C/Si on the surface of SP vs. those in the bulk of SP. Straight lines represent the case where the ratios are the same in both the surface and the bulk of SP. The letters " $A$ " and " $B$ " correspond to regions $A$ and $B$ in Fig. 8.

$=\frac{\left[\left(1+\frac{d r}{r}\right)^{3}-1\right] C_{\mathrm{coat}}^{M_{1}}+\left[1-\left(1+\frac{d r}{r}-\frac{d s}{r}\right)^{3}\right] C_{\mathrm{core}}^{M_{1}}}{\left[\left(1+\frac{d r}{r}\right)^{3}-1\right] C_{\mathrm{coat}}^{M_{2}}+\left[1-\left(1+\frac{d r}{r}-\frac{d s}{r}\right)^{3}\right] C_{\mathrm{core}}^{M_{2}}}$

when $d r>d s$

$=\frac{C_{\text {coat }}^{M_{1}}}{C_{\text {coat }}^{M_{2}}}$.

In the equations, $r, d r$ and $d s$ are radius of core, thickness of coat and detectable depth of surface analysis, respectively. $C_{\text {coat }}$ and $C_{\text {core }}$ are concentrations in coat and core, respectively. The locus of the $\left(M_{1} / M_{2}\right)_{\text {surface }}$ against the $\left(M_{1} / M_{2}\right)_{\text {bulk }}$ when the $d r$ increases is a function of the $d r / r$ ratio.

Calculation of the loci for the mixing of two different groups of particles of different sizes (Model b) The elemental ratios of $M_{1} / M_{2}$ for the surface and bulk analyses are

$$
\begin{array}{r}
\left(\frac{\left[M_{1}\right]}{\left[M_{2}\right]}\right)_{\text {bulk }}=\frac{C_{\mathrm{A}}^{M_{1}} n_{\mathrm{A}} r_{\mathrm{A}}^{3}+C_{\mathrm{B}}^{M_{1}} n_{\mathrm{B}} r_{\mathrm{B}}^{3}}{C_{\mathrm{A}}^{M_{2}} n_{\mathrm{A}} r_{\mathrm{A}}^{3}+C_{\mathrm{B}}^{M_{2}} n_{\mathrm{B}} r_{\mathrm{B}}^{3}} \\
=\frac{C_{\mathrm{A}}^{M_{1}} \frac{n_{\mathrm{A}}}{n_{\mathrm{B}}}\left(\frac{r_{\mathrm{A}}}{r_{\mathrm{B}}}\right)^{3}+C_{\mathrm{B}}^{M_{1}}}{C_{\mathrm{A}}^{M_{2}} \frac{n_{\mathrm{A}}}{n_{\mathrm{B}}}\left(\frac{r_{\mathrm{A}}}{r_{\mathrm{B}}}\right)^{3}+C_{\mathrm{B}}^{M_{2}}},
\end{array}
$$


a) The growing coat model

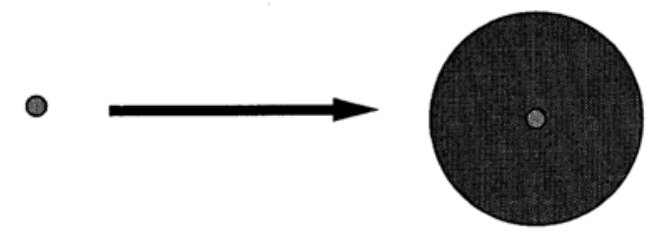

b) The two-particle mixing model

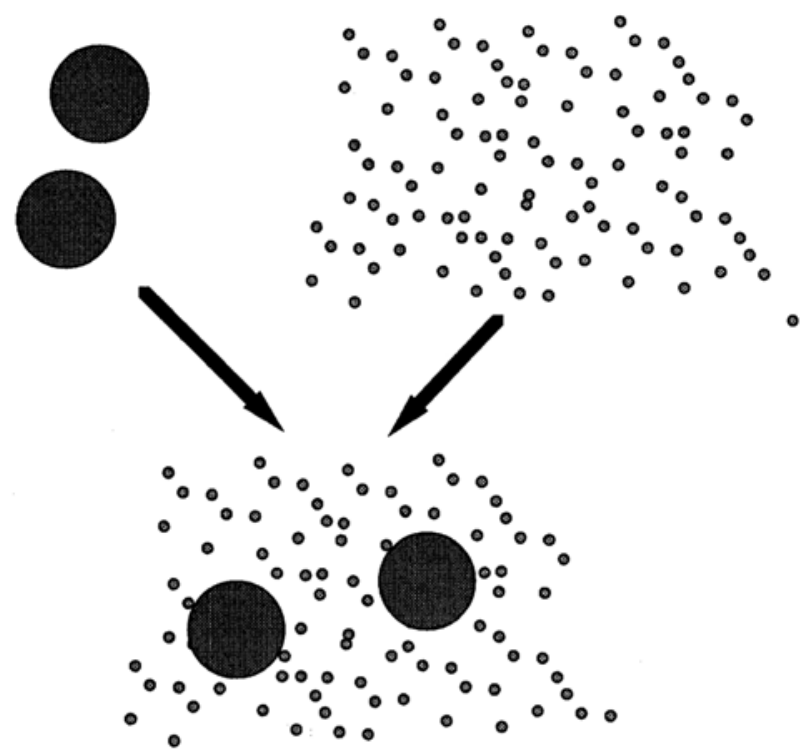

Fig. 5. The schematic diagrams of the particles for (a) the growing coat model and (b) the two-particle mixing model.

$$
\begin{aligned}
\left(\frac{\left[M_{1}\right]}{\left[M_{2}\right]}\right)_{\text {surface }}= & \frac{C_{\mathrm{A}}^{M_{1}} n_{\mathrm{A}} r_{\mathrm{A}}^{2}+C_{\mathrm{B}}^{M_{1}} n_{\mathrm{B}} r_{\mathrm{B}}^{2}}{C_{\mathrm{A}}^{M_{2}} n_{\mathrm{A}} r_{\mathrm{A}}^{2}+C_{\mathrm{B}}^{M_{2}} n_{\mathrm{B}} r_{\mathrm{B}}^{2}} \\
= & \frac{C_{\mathrm{A}}^{M_{1}} \frac{n_{\mathrm{A}}}{n_{\mathrm{B}}}\left(\frac{r_{\mathrm{A}}}{r_{\mathrm{B}}}\right)^{2}+C_{\mathrm{B}}^{M_{1}}}{C_{\mathrm{A}}^{M_{2}} \frac{n_{\mathrm{A}}}{n_{\mathrm{B}}}\left(\frac{r_{\mathrm{A}}}{r_{\mathrm{B}}}\right)^{2}+C_{\mathrm{B}}^{M_{2}}},
\end{aligned}
$$

where $n_{\mathrm{A}}, n_{\mathrm{B}}, r_{\mathrm{A}}, r_{\mathrm{B}}, C_{\mathrm{A}}$ and $C_{\mathrm{B}}$ are number, radius, concentration of particle-A and particle-B, respectively. The locus of the $\left(M_{1} / M_{2}\right)_{\text {surface }}$ against the $\left(M_{1} / M_{2}\right)_{\text {bulk }}$ when the $n_{\mathrm{A}} / n_{\mathrm{B}}$ ratio changes is a function of the $r_{\mathrm{A}} / r_{\mathrm{B}}$ ratio.
The results of the calculations are shown in Figs. 6(a) and (b). Naturally both ends of the loci by both of the models end with uniform particles, where the ratios for both surface and bulk are the same. The most remarkable difference between the two models is that the growing coat model has abrupt breaks in the loci, whereas the other does not. Both the models seem to be able to fit the observations of $\mathrm{Ti} / \mathrm{Si}$ and $\mathrm{Fe} / \mathrm{Si}$ fairly well. We can notice an abrupt break in the diagram for $\mathrm{Fe} / \mathrm{Si}$, although the points do not follow a clear line. With the limited accuracy of the present data and experiments and with the complexity of naturally occurring particles, however, it is difficult to 

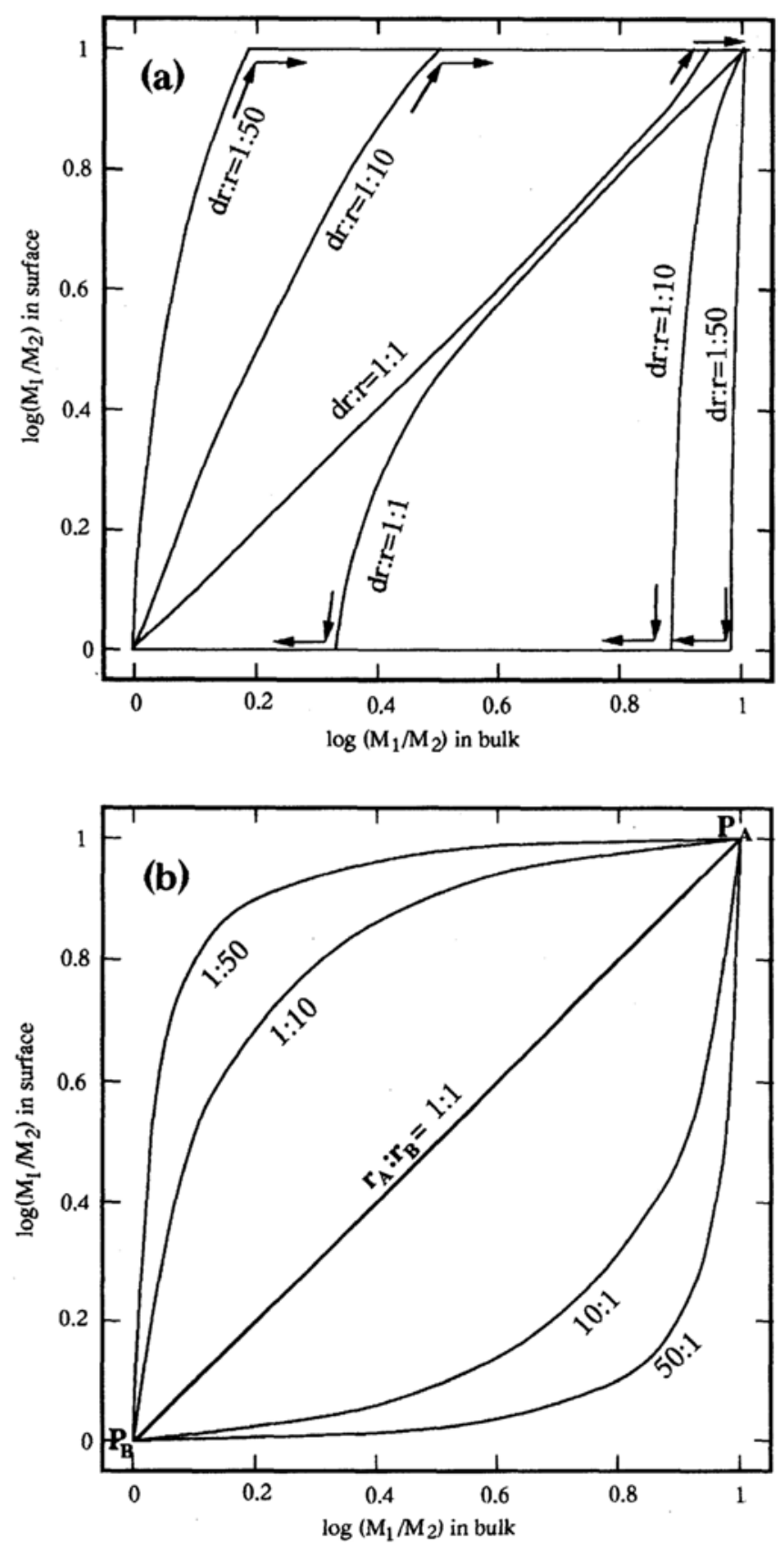

Fig. 6. Calculated loci for (a) the growing coat model and (b) the two-particle mixing model. (a) The start and end points of each line indicates the composition for core and coat, respectively. Ratios in the figure are ratios of detectable depth by XPS analysis against the radius of starting particles. (b) Both ends of each line correspond to the compositions of two particles, $P_{A}$ and $P_{B}$, which are the two end members of the model. The ratios in the figure are the radius ratio between the two particles. 
decide which model matches reality the best, but it is at least made clear that the shapes of these curves are not unexpected.

The points for $\mathrm{Mn} / \mathrm{Si}$ and $\mathrm{C} / \mathrm{Si}$ diagrams fall above the homogeneous line. We reproduced the loci which match the diagrams for $\mathrm{Mn} / \mathrm{Si}$ and $\mathrm{C} / \mathrm{Si}$ quite nicely by applying the two-particle mixing models with coated particles, not uniform particles, adopted as end members. The results of some calculations are shown in Fig. 7. It is impossible to explain the shape of the curves using other models unless a three-end-member system is introduced, which is not feasible for the reason that will be deduced from the next section. Therefore we conclude that there is at least a surface layer enriched in $\mathrm{C}$ and $\mathrm{Mn}$, and this proves for the first time the multiple structure of the single SP in estuarine areas.

Spatial change of composition of suspended particles One can divide the curves for $\mathrm{Ti} / \mathrm{Si}, \mathrm{Fe} / \mathrm{Si}$ and $\mathrm{Mn} / \mathrm{Si}$ into two regions (A and $\mathrm{B}$ in Figs. 4(a), (b), (c)). In one region the ratios for the surface change but those for the bulk remain fairly constant (region B in Fig. 4), the other is where the ratios for the surface is fairly constant but those for the bulk vary (region A in Fig. 4). The former corresponds well to deeper water and the latter to near- surface water (see Fig. 8). The assignment of the two regions is almost the same for these three ratios, except for Station 1. Station 1 lies in region A for $\mathrm{Mn} / \mathrm{Si}$, but in region $\mathrm{B}$ for $\mathrm{Ti} / \mathrm{Si}$ and $\mathrm{Fe} / \mathrm{Si}$. The clear spatial separation of the two regions strongly indicates that it is better to use the twoend-member system in this case and that the change of SP takes place vertically not horizontally. Taking the results of the calculation for the two models into account, it can be concluded that in near-surface water there are many SP, and that these make the results of surface composition analysis rather constant (SP with thicker coat or $\mathrm{SP}$ of smaller size) in terms of $\mathrm{Ti} / \mathrm{Si}, \mathrm{Fe} / \mathrm{Si}$ and $\mathrm{Mn} / \mathrm{Si}$ than in deeper water.

Silica in suspended particles It is worth noting that both the bulk $\mathrm{Ti} / \mathrm{Si}$ and $\mathrm{Fe} / \mathrm{Si}$ ratios for region $\mathrm{B}$ coincide with those for average crust $(\mathrm{Ti} / \mathrm{Si}=0.016$ and $\mathrm{Fe} / \mathrm{Si}=0.18$, from Mason and Moore, 1982). They may be mainly determined by the presence of silicate minerals. In fact, we observed various silicate minerals in SP in this area (Akagi et al., 1988). The ratio of $\mathrm{Mn} / \mathrm{Si}$ for region $\mathrm{B}$ is, however, much higher than that for average crust $(0.0034$, from Mason and Moore, 1982).

If we follow this line of discussion, one end member (the core for the growing coat model and
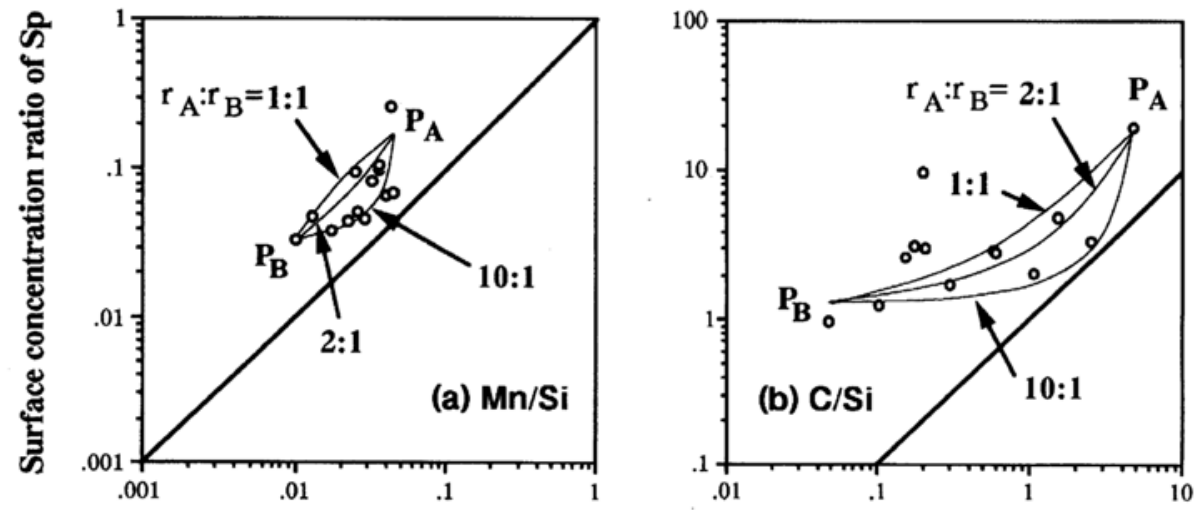

Bulk concentration ratio of Sp

Fig. 7. Calculated loci to fit the observed trends of (a) Mn/Si and (b) C/Si by the two-particle mixing model using coated particles as end members. The surface and bulk compositions are calculated by the compositions of the coats and cores, respectively, assuming that the depths of the coats are negligibly small. The ratios in the figure are the radius ratio between the two particles. 

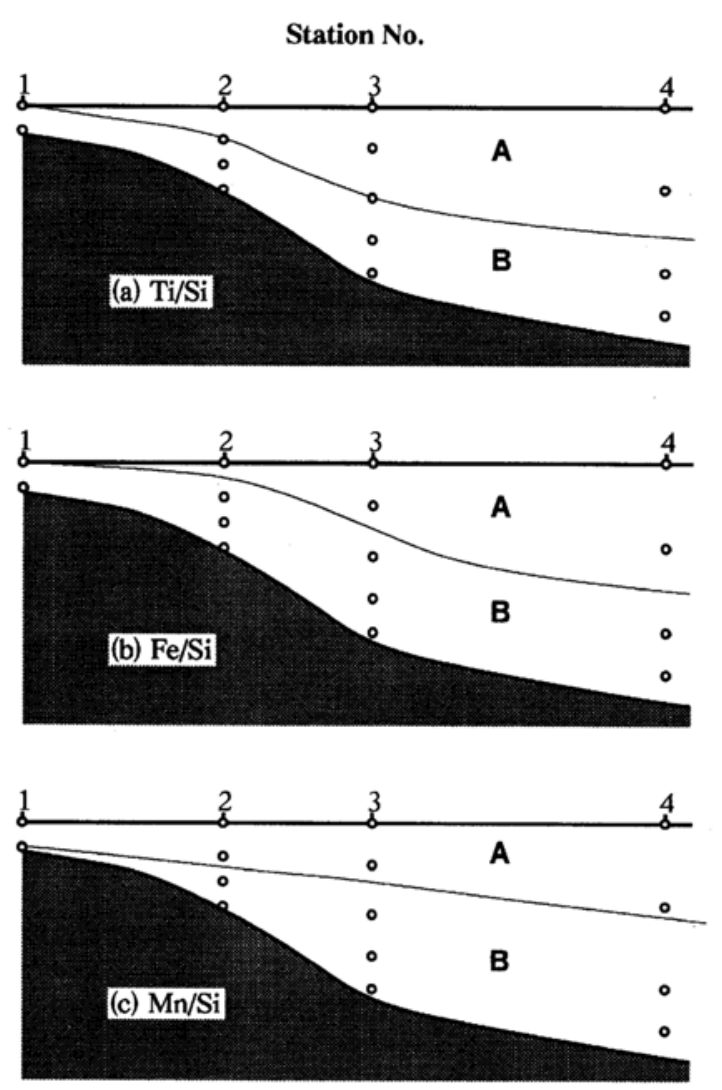

Fig. 8. Cross-sections demonstrating regions $A$ and $B$ in terms of (a) $\mathrm{Ti} / \mathrm{Si}$, (b) $\mathrm{Fe} / \mathrm{Si}$ and (c) C/Si (see text).

the larger particles for the two-particle mixing model) had high $\mathrm{Ti} / \mathrm{Si}$ and $\mathrm{Fe} / \mathrm{Si}$ ratios, perhaps determined by the composition of silicate minerals, and the other end member (the coat for the growing coat model and the smaller particles for the two-particle mixing model) is likely to be amorphous silica (Willey, 1975) which is enriched in $\mathrm{Si}$.

There is an alternative interpretation based on the desorption of elements from the surface, which was reported for some elements by Li et al. (1984). Simple desorption from the increasing depth of surface gives a similar curve as shown in Fig. 6(a). In the case of $\mathrm{Ti} / \mathrm{Si}$, the desorption from the surface of SP is feasible, because Ti gave an increase in concentration in water of the same salinity (Fig. 9) and $\mathrm{Ti}$ can form stable species of the oxide ion enabling $\mathrm{Ti}$ to dissolve in seawater. However the same mechanism may not be operative in the case of $\mathrm{Fe} / \mathrm{Si}$ since iron shows no evidence of desorption (Fig. 9). To explain both the curves of $\mathrm{Fe} / \mathrm{Si}$ and $\mathrm{Ti} / \mathrm{Si}$ at the same time, therefore, we reach the conclusion that an Si-enriched particle is formed. Manganese in suspended particles In the case of $\mathrm{Mn} / \mathrm{Si}$ the following interpretation is plausible. Unlike the other elements, the behaviour of $\mathrm{Mn}$ is strongly associated with the redox potential of water. Manganese can be supplied not only from river water but also from sediment of reduced condition (Li et al., 1984; Saager et al., 1989). Such Mn as supplied from sediment is divalent, but is soon oxidized into Mn(IV), which is a fairly unstable species in seawater and stabilizes itself by being adsorbed onto SP. A relatively higher concentration of $\mathrm{Mn}$ in suspended matter than that in nearby sediment was reported (Feely et al., 1983). In the near-surface water of the area studied, most of the Mn may originate from the river and may be quickly adsorbed onto SP as deduced from the dramatical decrease in its dissolved concentration. On the other hand, in deeper water Mn may be from the sediment, because the concentration of $\mathrm{Mn}$ in the bottom layer was slightly higher than in the water above (Table 4), and such Mn was again adsorbed onto SP. The amount of absorbed $\mathrm{Mn}$ is much less in deeper water than in nearsurface water from the gradient of dissolved concentration (Fig. 9).

The SP in regions A and B are considered to have the different histories of the surface coat development, and thus they are different with respect to $\mathrm{Mn} / \mathrm{Si}$ and perhaps the thickness of $\mathrm{Mn}$ coat as well. This idea supports our explanation on the shape of the curves between surface and bulk for $\mathrm{Mn} / \mathrm{Si}$ (Figs. 4 and 7), which is based on the mixing of two different coated particles.

Carbon in suspended particles Figure 4(d) compares $\mathrm{C} / \mathrm{Si}$ ratio between bulk and surface. Carbon measured in the bulk of SP is organic C, while that measured on the surface of SP is total C. However, one can regard the bulk measurement as total carbon, since the amount of inorganic $\mathrm{C}$ in SP from this area is negligible relative to organic C. Plots for C/Si (Fig. 4(d)) are spread over a rather 

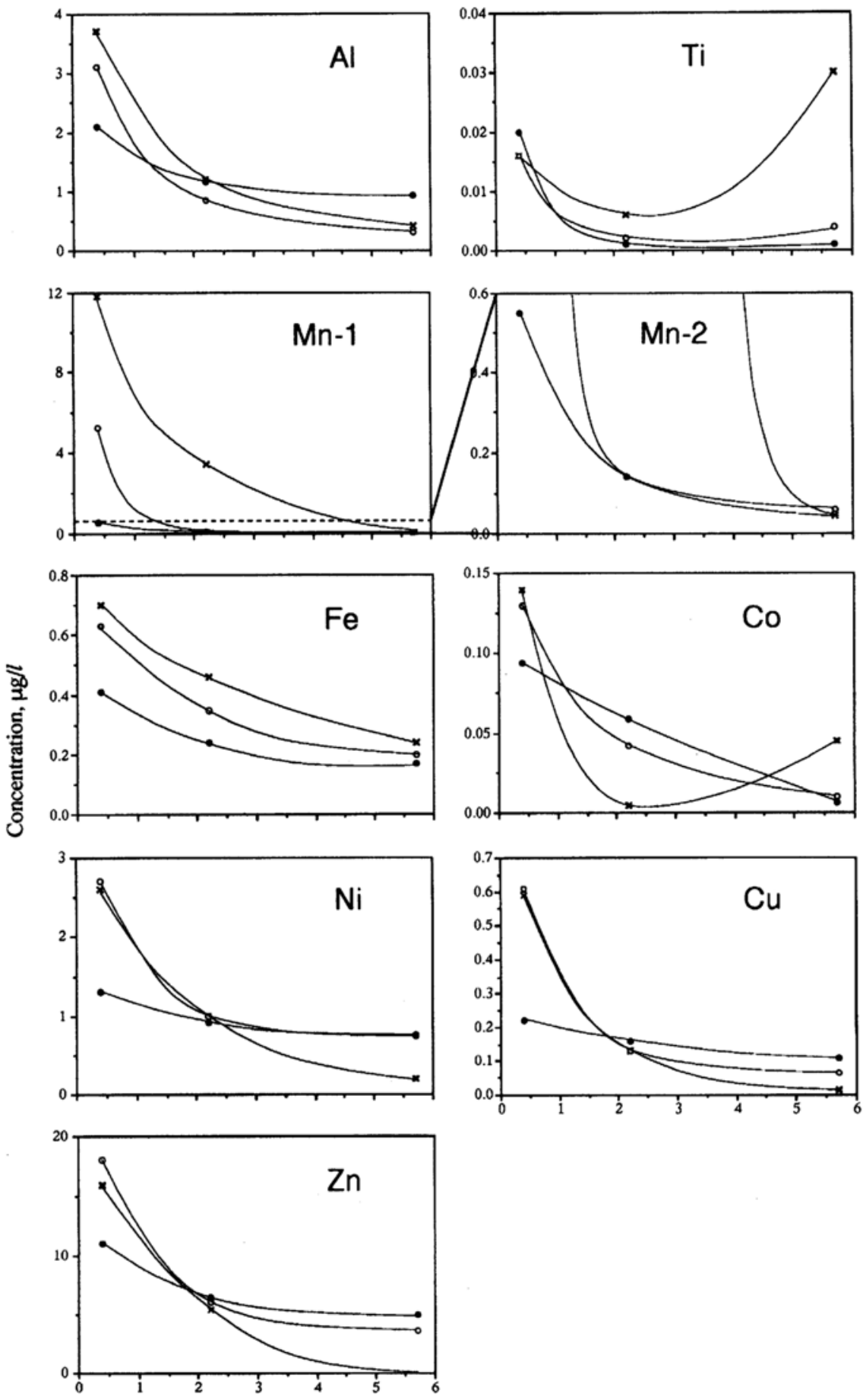

Distance from the river mouth, $\mathrm{km}$

Fig. 9. Calculated concentrations of dissolved trace metals in waters from the Tamagawa River estuary and Tokyo Bay at certain salinities as a function of distance from the Tamagawa River mouth. Salinity 30, x: 31 , O: 32 ,

-. Mn-2 is an expanded version of Mn-1. 
Table 4. Concentrations $(\mu \mathrm{g} / \mathrm{l})$ of dissolved trace metals in the Tamagawa River estuary and Tokyo Bay (data from Akagi and Haraguchi, 1984)

\begin{tabular}{cccccclllr}
\hline $\begin{array}{c}\text { Station } \\
\text { No. }\end{array}$ & $\begin{array}{c}\text { Depth } \\
(\mathrm{m})\end{array}$ & $\mathrm{Al}$ & $\mathrm{Ti}$ & $\mathrm{Mn}$ & $\mathrm{Fe}$ & $\mathrm{Co}$ & $\mathrm{Ni}$ & $\mathrm{Cu}$ & $\mathrm{Zn}$ \\
\hline \multirow{2}{*}{1} & 0 & 3.0 & 0.014 & 22.7 & 1.85 & 0.040 & 0.67 & 0.32 & 4.3 \\
& 3 & 5.9 & 0.008 & 35.0 & 0.89 & 0.27 & 3.5 & 1.1 & 14.2 \\
2 & 0 & 10.6 & 0.025 & 79.9 & 1.51 & 0.30 & 1.3 & 0.39 & 3.7 \\
& 4 & 2.6 & 0.015 & 1.31 & 0.58 & 0.12 & 2.8 & 0.62 & 18.4 \\
& 7 & 2.0 & 0.021 & 0.36 & 0.37 & 0.087 & 0.99 & 0.12 & 8.5 \\
& 10 & 2.1 & 0.006 & 0.72 & 0.27 & 0.067 & 1.1 & 0.15 & 5.7 \\
3 & 0 & 8.1 & 0.041 & 42.1 & 0.83 & 0.29 & 1.4 & 0.36 & 2.5 \\
& 5 & 0.62 & 0.003 & 0.13 & 0.43 & 0.030 & 1.0 & 0.11 & 5.6 \\
& 11 & 1.4 & 0.000 & 0.15 & 0.15 & 0.073 & 0.86 & 0.18 & 6.8 \\
& 16 & 1.9 & 0.007 & 0.12 & 0.38 & 0.044 & 0.62 & 0.12 & 4.8 \\
& 20 & 2.0 & 0.000 & 0.12 & 0.17 & 0.016 & 0.67 & 0.18 & 7.8 \\
4 & 0 & 0.39 & 0.025 & 0.046 & 0.23 & 0.038 & 0.30 & 0.025 & 0.67 \\
& 10 & 0.30 & 0.001 & 0.061 & 0.19 & 0.007 & 0.79 & 0.072 & 4.0 \\
& 20 & 2.3 & 0.000 & 0.008 & 0.11 & 0.003 & 0.70 & 0.20 & 6.4 \\
& 25 & 1.7 & 0.000 & 0.048 & 0.10 & 0.000 & 0.33 & 0.12 & 5.9 \\
\hline
\end{tabular}

wider area than those for $\mathrm{Ti} / \mathrm{Si}, \mathrm{Fe} / \mathrm{Si}$ and $\mathrm{Mn} / \mathrm{Si}$, suggesting that $\mathrm{SP}$ are rather heterogeneous in terms of $\mathrm{C} / \mathrm{Si}$. $\mathrm{C} / \mathrm{Si}$ on the surface of SP is always higher than in the bulk indicating the enrichment of $\mathrm{C}$ on surface.

It is worth mentioning that the points for surface samples begin at the left of the figure and move to the right in the direction of water flow, and the distance of each point from the homogeneous line decreases with increasing distance offshore. This reflects the fact that the bulk chemical composition of SP is becoming richer in carbon (Table 2), thus approaching that of the surface. The SP occurring further offshore may have originated in the coastal area and such SP may have organic cores from the outset, and the SP from the river, on the other hand, may have mineral cores and thin organic coats. As previously discussed, the shape of the curve in Fig. 4 reflects the mixing of such two different particles.

\section{Kinetic effect of the surface of suspended particles on the dissolved trace elements}

Relationships between the distribution of dissolved trace elements and the surface composition of SP were studied for evidence of kinetic interaction between them. If adsorption of dissolved species onto the surface of SP occurs, the rate of adsorption for element $M$ is proportional to the concentration of the dissolved element $\left(C_{M}\right)$ and the area of specific adsorbing sites available $\left(S_{\mathrm{AS}}\right)$ :

$$
-\frac{d C_{M}}{d t}=k C_{M} S_{\mathrm{AS}}
$$

where $k$ is a rate constant. The effect of dilution, diffusion and advection can be neglected if one compares the concentrations at the same salinity. This equation rearranges to

$$
-\frac{d C_{M}}{d t C_{M}}=k S_{\mathrm{AS}} .
$$

Unfortunately we have no data concerning time. Therefore we have used distance data $(L)$ instead: i.e., the relation between $-d C_{M} /\left(d L C_{M}\right)$ and $S_{\mathrm{AS}}$ was studied for each element. This method had to be used to draw the most benefit from the data set which lacked accurate data of the flow rate in this area. The data for water whose salinity was greater than 33 were not used in this discussion, excluding the data for the bottom water at Stns. 3 and 4 . It is to reduce some possible errors due to bottom water flow toward the river mouth.

The concentrations for certain salinities $(30,31$ 
Table 5. Correlation coefficients $\left(r^{2}\right)$ between the areas of elements on the surface of suspended particles

\begin{tabular}{cccccccc}
\hline & $\mathrm{O}$ & $\mathrm{N}$ & $\mathrm{Si}$ & $\mathrm{Al}$ & $\mathrm{Ti}$ & $\mathrm{Fe}$ & $\mathrm{Mn}$ \\
\hline $\mathrm{C}$ & \multirow{2}{*}{0.58} & 0.96 & 0.53 & 0.14 & 0.22 & 0.16 & 0.56 \\
$\mathrm{O}$ & & 0.63 & 0.99 & 0.77 & 0.84 & 0.78 & 0.94 \\
$\mathrm{~N}$ & & & 0.58 & 0.18 & 0.26 & 0.19 & 0.63 \\
$\mathrm{Si}$ & & & & 0.78 & 0.85 & 0.78 & 0.94 \\
$\mathrm{Al}$ & & & & & 0.97 & 1.00 & 0.64 \\
$\mathrm{Ti}$ & & & & & & 0.97 & 0.71 \\
$\mathrm{Fe}$ & & & & & & & 0.68 \\
\hline
\end{tabular}

and 32) at each station were calculated by interpolation from the data in Table 4 . The concentration gradient $\left(d C_{M} / d L\right)$ for each metal was determined by fitting the points at each salinity shown in Fig. 9 by exponential function $\left(a e^{-b L}+c: a, b\right.$ and $c$ are constants).

For convenience's sake, the surface area of an element on the surface of SP is defined as the product of its molar fraction and the total surface area of the SP (Table 2). The latter was greatest in surface waters, and was generally found to decrease with distance from the river mouth. The total surface areas of SP and the surface area of each element on SP were recalculated for salinity of 30, 31 and 32. As can be seen from Table 5, the surface areas of $\mathrm{C}$ and $\mathrm{N}, \mathrm{Si}$ and $\mathrm{O}$, and $\mathrm{Fe}$ and $\mathrm{Al}$ are strongly correlated with each other, indicating that there is no point in classifying adsorbing sites into more than three or four types; therefore we have considered surface areas of $\mathrm{C}+\mathrm{N}$, $\mathrm{Al}+\mathrm{Fe}, \mathrm{Si}$ and $\mathrm{Mn}$ as areas representing possible adsorbing sites.

Correlations between $d C_{M} /\left(d L C_{M}\right)$ and surface area of elements are listed in Table 6. In Fig. 10 some examples of the correlation are demonstrated. It should be noted from Table 6 that iron appears not to have any specific site for its adsorption. We expected iron to be adsorbed onto the organicrich surface of SP, as Sholkovitz et al. (1978) demonstrated interaction between humic substances and iron, but it did not seem to occur in the present case. The concentration gradients in Fig. 9 seem to depend largely on the concentrations of itself. Although it is unclear from the present limited results, it is likely that Fe was "spontaneously"
Table 6. Correlation coefficients $\left(r^{2}\right)$ between $d C_{M} /$ $\left(d L C_{M}\right)$ and $S_{A S}$ (see text)

\begin{tabular}{ccccc}
\hline$d C_{M} /\left(d L C_{M}\right)$ & \multicolumn{4}{c}{$S_{\mathrm{AS}}$, surface area of adsorbing site } \\
\cline { 2 - 5 }$M$ & $\mathrm{C}+\mathrm{N}$ & $\mathrm{Si}$ & $\mathrm{Al}+\mathrm{Fe}$ & $\mathrm{Mn}$ \\
\hline $\mathrm{Al}$ & 0.00 & 0.39 & 0.65 & 0.39 \\
$\mathrm{Mn}$ & 0.73 & 0.11 & 0.00 & 0.21 \\
$\mathrm{Fe}$ & 0.02 & 0.10 & 0.27 & 0.14 \\
$\mathrm{Co}$ & 0.06 & 0.06 & 0.07 & 0.14 \\
$\mathrm{Ni}$ & 0.11 & 0.56 & 0.57 & 0.60 \\
$\mathrm{Cu}$ & 0.05 & 0.58 & 0.62 & 0.59 \\
$\mathrm{Zn}$ & 0.32 & 0.50 & 0.55 & 0.63 \\
\hline
\end{tabular}

removed from the water onto or incorporated into SP. Colloid formation is one possibility for the removal of $\mathrm{Fe}$, as reported elsewhere (Fox and Wofsy, 1983; Hunter and Leonard, 1988).

The combined surface areas of carbon and nitrogen, $S_{\mathrm{C}+\mathrm{N}}$, did not show a particularly high correlation with any metal except $\mathrm{Mn}$ in solution. Manganese may be adsorbed onto the organic-rich surface of SP. The surface area of manganese, $S_{\mathrm{Mn}}$, showed the good correlations for $\mathrm{Ni}, \mathrm{Cu}$ and $\mathrm{Zn}$ (Table 6), indicating that $\mathrm{Mn}$ on the surface might be an effective adsorber of such elements. The surface area of $\mathrm{Si}, S_{\mathrm{Si}}$, also gave significant correlations for $M=\mathrm{Ni}, \mathrm{Cu}$ and $\mathrm{Zn}$. Willey (1975) and Pages (1978) have reported the interaction of aluminium and silicate, suggesting that amorphous silica can incorporate dissolved trace elements. It seems likely that these three elements are adsorbed onto amorphous silica surface. However, the surface area of $\mathrm{Si}$ correlates well with that of $\mathrm{Mn}$ (Table 5), so their effects cannot be entirely separated. $S_{\mathrm{Al}+\mathrm{Fe}}$ showed significant correlations for 


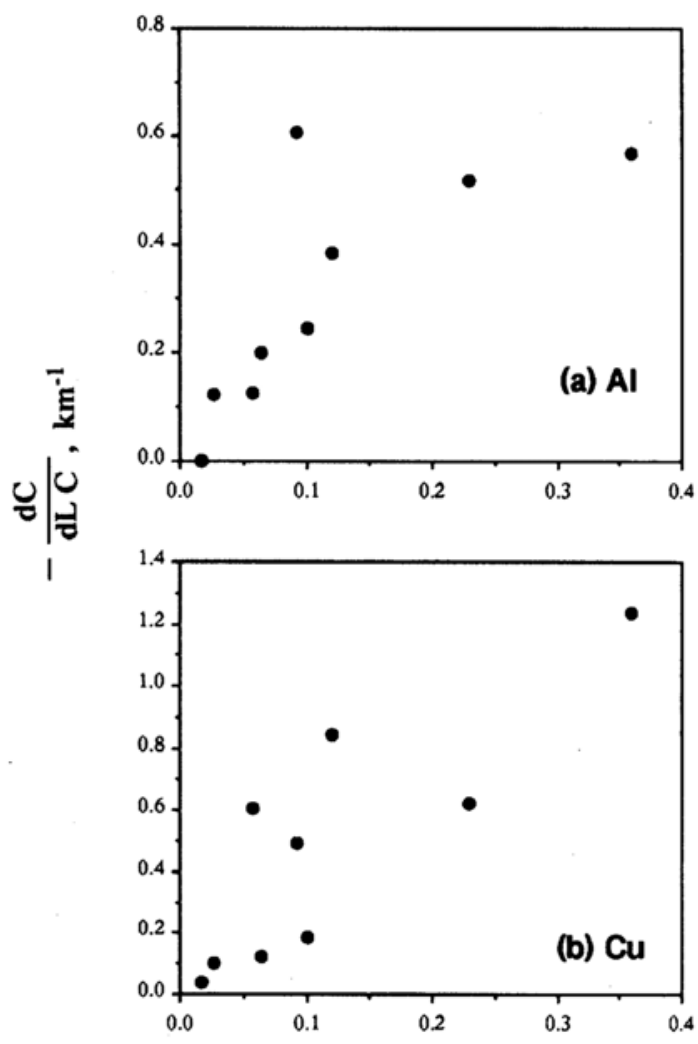

Surface area of $\mathrm{Al}+\mathrm{Fe}, \mathrm{cm}^{2} \mathrm{l} \cdot \mathrm{l}$
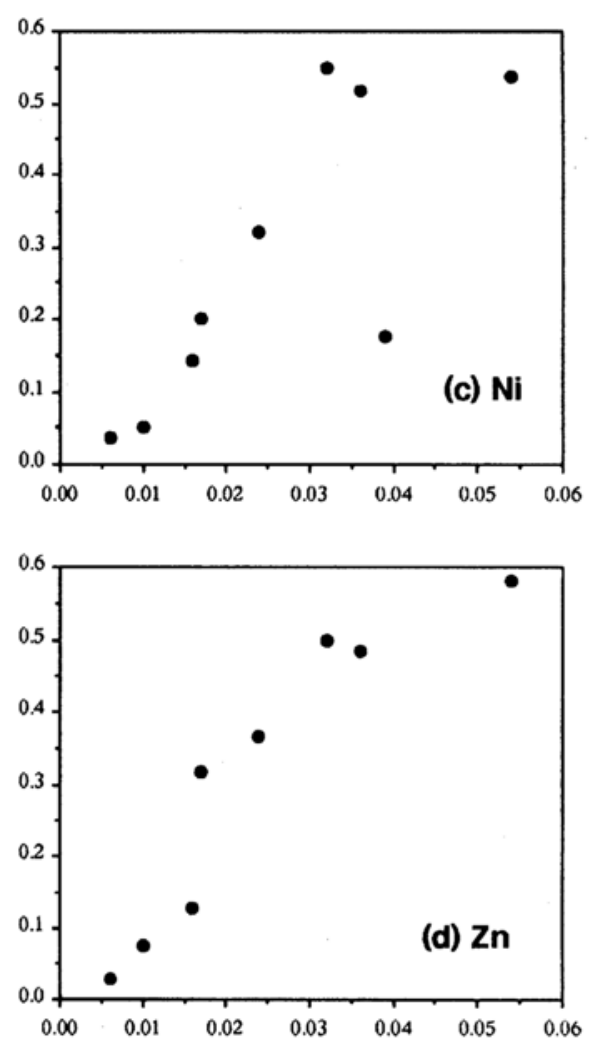

Surface area of $\mathrm{Mn}, \mathrm{cm}^{2} \mathrm{l}^{-1}$

Fig. 10. Correlation between $d C_{M} /\left(d L C_{M}\right)$ and $S_{A l+F e}[M=$ (a) $A l$, (b) $C u]$ and between $d C_{M} /\left(d L C_{M}\right)$ and $S_{M n}$ $[M=$ (c) $\mathrm{Ni}$, (d) $\mathrm{Zn}]$. The surface areas of $\mathrm{C}+\mathrm{N}, \mathrm{Al}+\mathrm{Fe}$, Si and $\mathrm{Mn}$ are considered as areas representing possible adsorption sites for the reason mentioned in the text.

$M=\mathrm{Al}, \mathrm{Ni}, \mathrm{Cu}$ and $\mathrm{Zn}$. These elements may be adsorbed onto the surface of substances rich in $\mathrm{Al}$ and/or Fe, but again this is not conclusive because the surface areas of $\mathrm{Fe}$ and $\mathrm{Al}$ also correlate with those of $\mathrm{Si}$ and $\mathrm{Mn}$ to some extent (Table 5).

Although only four examples are shown in Fig. 10 , most correlations between $-d C_{M} /\left(d L C_{M}\right)$ and $S_{\text {AS }}$ (including those not shown in Fig. 10) show a curving relationship rather than a straight one. The two extreme right points in all the figures are for Station 2, where water was supposed to flow quicker than at Stations 3 and 4 . If we could measure and allow for the speed of the water flow, a more linear correlation would hopefully be obtained.

The removal of metals from the water by the surface of SP is actually the total effect of adsorp- tion onto each type of site on the surface. However, the precision and accuracy of the present discussion, involving several assumptions, limits such an analysis, and we should not rely too much on such correlations with the surface areas of individual elements. Nevertheless, we can deduce from these correlations that the surface of SP is an important adsorbent for dissolved trace metals and that $\mathrm{Mn}, \mathrm{Al}$ or/and $\mathrm{Fe}$ may provide the effective sites for adsorption of some metals.

The concentration of dissolved species would not be affected by the settling out of the particles if there were no interaction between the dissolved species and the particles. The present results suggest that the adsorption of dissolved species on the surface of particles is operative and actually affects the distribution of the dissolved species. 


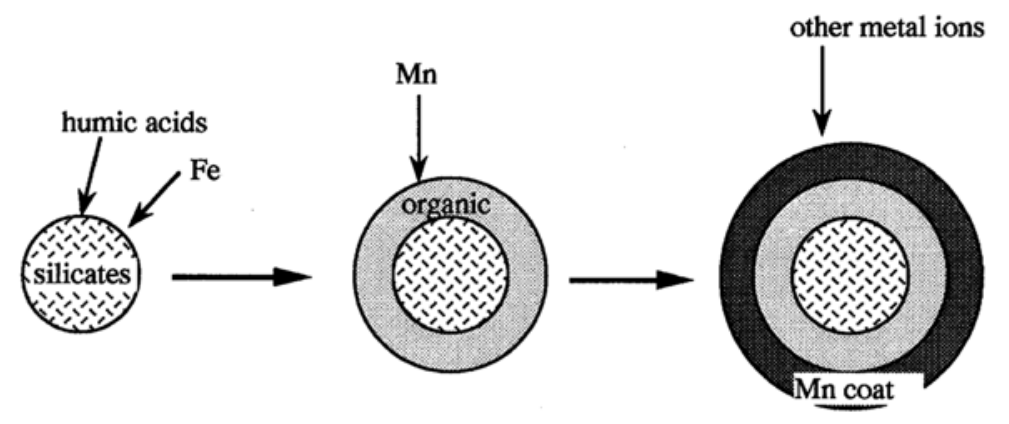

Fig. 11. Schematic diagram to demonstrate the adsorption of dissolved species from the estuarine water and the development of a surface coat on suspended particles.

\section{CONCLUSIONS}

1) On the surface of SP in estuarine and coastal waters of Tokyo Bay, there is a layer rich in organic matter. The concentration of organic carbon in SP increases with distance offshore.

2) Chemical analysis suggests that the organic material of the surface layer may be humic acids.

3) Manganese is enriched in the surface layer relative to the bulk composition of SP, especially in deeper water.

4) Silica is adsorbed on the surface of the SP, especially in near-surface waters.

5) The comparison of elemental composition between bulk and surface revealed that $\mathrm{Mn}$ in the SP reflected the mixing of the particles at the surface and bottom waters and that $\mathrm{C}$ in the SP was decided mainly by the mixing of the particles occurring at the river mouth and offshore.

6) Some dissolved trace metals are adsorbed onto the surface of SP. Oxides of $\mathrm{Mn}, \mathrm{Al}$ and/or $\mathrm{Fe}$ on the surface are more effective removers of trace metals from solution than a humic acid on the surface. The humic acid, however, may adsorb dissolved Mn.

7) In the light of these conclusions, a threestep model (as illustrated in Fig. 11) can be put forward for the adsorption of dissolved element on the developing surface of SP. At first, silicate minerals are introduced into an estuarine system via. a river. On the silicates an organic coat might form, although this step is not inferred from our present study. Nextly the organic coat adsorbs manganese and a manganese-rich coat forms. The manganese-rich coat then adsorbs other dissolved metals such as $\mathrm{Ni}, \mathrm{Cu}$, and $\mathrm{Zn}$ rather unselectively.

Acknowledgments-The authors thank Prof. T. Yoshida, Tokyo University of Fisheries, and his coworkers for providing their valuable data on particulate organic carbon and for kind help in sampling, and Dr. M. Soma and Dr. H. Seyama, National Institute for Environmental Science, for help in XPS measurement. We also thank Dr. J. Phillips, the Open University, for the critical and constructive comments on the manuscript. Thanks are also extended to Prof. K. Fuwa, former President of National Institute for Environmental Sciences, and Prof. H. Tsubota, formerly of Hiroshima University, for discussions and for encouraging this study. We would like to express thanks to the crew of the Hiyodori Observation boat, Tokyo University of Fisheries, for their help in sampling. The present research was supported by a Grant-in-Aid from the Ministry of Education, Science and Culture, Japan.

\section{REFERENCES}

Akagi, T., Fuwa, K. and Haraguchi, H. (1985a) Surface analysis of suspended particles in estuarine and coastal waters using X-ray photoelectron spectroscopy. Chem. Lett. 1985, 1929-1932.

Akagi, T. and Haraguchi, H. (1984) Distribution and behaviours of trace heavy metals in the Tama River Estuary and Tokyo Bay. Geochemistry (Chikyukagaku) 18, 81-88.

Akagi, T. and Haraguchi, H. (1986) Geochemical characterization of suspended particles in estuarine and coastal seawater by X-ray fluorescence spec- 
trometry. Chem. Lett. 1986, 1141-1144.

Akagi, T., Haraguchi, H. and Fuwa, K. (1985b) Simultaneous multielement determination of trace metals in seawater by inductively-coupled plasma atomic emission spectrometry after coprecipitation with gallium. Anal. Chim. Acta 177, 139-151.

Akagi, T., Haraguchi, H. and Tsubota, H. (1988) A study on mineral compositions of suspended particles in coastal and estuarine water using X-ray diffractiometry. Chem. Lett. 1988, 331-334.

Bewers, J. M. and Yeats, P. A. (1981) Behaviour of trace metals during estuarine mixing. River Inputs to Ocean System, 103-115, UNEP and UNESCO.

Burton, J. D. (1976) Basic properties and processes in estuarine chemistry. Estuarine Chemistry (Burton, J. D. and Liss, P. S., eds.), 1-36, Academic Press, London.

Duinker, J. C. (1980) Suspended matter in estuaries: adsorption and desorption process. Chemistry and Biochemistry of Estuarines (Olausson, E. and Cato, I., eds.), 121-151, John Wiley \& Sons, Chichester.

Feely, R. A., Massoth, G. J., Panlson, A. J. and Gendron, J. F. (1983) Possible evidence for enrichment of trace elements in the hydrous manganese oxide phases of suspended matter from an urbanized embayment. Estuar. Coast. Shelf Sci. 17, 693-708.

Fox, E. L. and Wofsy, S. C. (1983) Kinetics of removal of iron colloids from estuaries. Geochim. Cosmochim. Acta 47, 211-216.

Hunter, K. A. and Leonard, M. W. (1988) Colloid stability and aggregation in estuarines: 1. Aggregation kinetics of riverine dissolved iron after mixing with seawater. Geochim. Cosmochim. Acta 52, 1123-1130.

Li, Y.-H., Burkhardt, L. and Teraoka, H. (1984) Desorption and coagulation of trace elements during estuarine mixing. Geochim. Cosmochim. Acta 48, 18791884.

Maison, B. and Moore, C. B. (1982) The structure and composition of the earth. Principles of Geochemistry,
28-64, John Wiley \& Sons, New York.

Moran, S. B. and Moore, R. M. (1989) The distribution of colloidal aluminum and organic carbon in coastal and open ocean waters off Nova Scotia. Geochim. Cosmochim. Acta 53, 2519-2527.

Morris, A. W., Howland, R. J. M. and Bale, A. J. (1986) Dissolved aluminium in Tamar Estuary, Southwest England. Geochim. Cosmochim. Acta 50, 187-197.

Okami, N., Kishino, M., Sugihara, S., Takematsu, N. and Unoki, S. (1982) Analysis of ocean color spectra (III) - measurements of optical properties of sea water. J. Oceanogr. Soc. Jpn. 38, 362-372.

Pages, T. (1978) Reversible control of aqueous aluminium and silica during the irreversible evolution of natural water. Geochim. Cosmochim. Acta 42, 14871493.

Saager, P. M., deBaar, H. J. and Burkill, P. H. (1989) Manganese and iron in Indian Ocean waters. Geochim. Cosmochim. Acta 53, 2259-2267.

Saito, Y. and Hayano, S. (1980) Distribution of oxygencontaining functional groups and elements in humic acids from marine sediments. J. Oceanogr. Soc. Jpn. 36, 59-67.

Seyama, H. and Soma, M. (1982) Analysis of the surface chemical composition of pond sediment by Xray photoelectron spectroscopy. Res. Rep. Nat. Inst. Environ. Stud. 38, 23-38.

Sholkovitz, E. R. (1976) Flocculation of dissolved organic and inorganic matter during the mixing of river water and sea water. Geochim. Cosmochim. Acta 40, 831-845.

Sholkovitz, E. R., Boyle, E. A. and Price, N. B. (1978) The removal of dissolved humic acids and iron during estuarine mixing. Earth Planet. Sci. Lett. 40, 130-136.

Takematsu, N., Kishino, M. and Okami, N. (1979) Optical properties and modeling of turbidity components in sea water (I). La mer. 17, 117-126.

Willey, J. D. (1975) Silica-alumina interactions in seawater. Mar. Chem. 3, 241-251. 